\title{
Neural Stem Cells of the Neuroepithelium Direct Newborn Neurons' Axons Electrically: Galvanotropism Precedes Chemotropism
}

\section{Masayuki Yamashita*}

Center for Medical Science, International University of Health and Welfare, Kitakanemaru, Ohtawara, Japan

Keywords: Stem Cells; Neurons; Neural stem cells; Nervous system; Galvanotropism

\section{Short Communication}

Growing axons are directed not only by chemical signals but also by electric fields in a process known as galvanotropism. The axons of embryonic brain, spinal cord, and retina extend along the extracellular voltage gradient towards the cathode. During embryonic development neuroepithelial cells function as neural stem cells. The neuroepithelial cells have epithelial type sodium channels $(\mathrm{ENaC})$, and the sodium transport by these cells produces positive direct current (DC) potentials within the neuroepithelium. The amplitude of the DC potential is large at the area where neuroepithelial cells proliferate. The central nervous system develops as neuroepithelial cells proliferate, during which period the neurons that issue long-distance travelling axons are born first. Since neuroepithelial cells generate positive DC potentials, the resultant electric field orients the newborn neurons' axons in the direction against the area where the neuroepithelial cells most actively proliferate.

The prevailing belief is currently that growing axons are guided by attraction or repulsion in response to various chemical signals (chemotropism). However, it has also been demonstrated that the axons of embryonic nervous systems extend along the extracellular voltage gradient in a process termed 'galvanotropism' [1]. The galvanotropic behavior was demonstrated in cultures as early as 1920. By applying an extracellular electric field, growing axons are directed towards the cathode [2]. However, since the previous studies used culture systems to which exogenous electric fields were applied, it has been unknown whether electric fields are formed in embryonic nervous systems, or whether newborn neurons use galvanotropism to orient their axons.

The central nervous system (CNS), which includes the brain, spinal cord, and retina, is derived from the neural tube. The neural tube is formed of the neuroepithelium. During embryonic CNS development, neuroepithelial cells act as neural stem cells by renewing themselves and producing neurons. Neuroepithelial cells have a polarized structure: their apical process faces the ventricle, while the furthest portion of their basal process makes contact with the basement membrane. The neuroepithelial cell has various types of ion channels [3-5], including epithelial type sodium channels (ENaC) [6]. $\mathrm{Na}^{+}$ions enter the neuroepithelial cells through $\mathrm{ENaC}$ from the apical side, and are extruded by $\mathrm{Na}^{+}-\mathrm{K}^{+}$pumps in the basal region. Thus, the sodium transport by neuroepithelial cells establishes a positive DC potential inside the neuroepithelium [6,7].

The positive DC potential in the retinal neuroepithelium forms extracellular voltage gradients in the optic cup [7]. The amplitude of the DC potential is largest at the periphery of the retina, where the retinal neuroepithelial cells most actively proliferate. The DC potential is almost null at the ventral portion of the optic cup, where the future optic disc is formed. Retinal ganglion cells (RGC), the first type of retinal neurons, are born at the central part of the optic cup. They issue their axons in the basal region of the retinal neuroepithelium. Then, the RGC axons grow towards the future optic disc. The mechanism for orienting these RGC axons remained unknown [8]. However, the disruption of the endogenous voltage gradient by applying amiloride, a blocker for $\mathrm{ENaC}$ [6], results in erroneous path-finding of RGC axons [7], suggesting that the electric field plays a pivotal role in orienting newborn RGC axons.

During CNS development, the neurons that issue long-distance travelling axons, such as descending fibers and optic nerves, are born first, and these axons start to extend in their own defined directions almost simultaneously at various parts of the CNS [9]. The mechanism for orienting these long-distance axons has been unknown; there is little evidence for long-range chemical cues [10]. The present short commentary points to the electrical activity of neuroepithelial cells and the role for the electric field in axon orientation. Considering that the electric field is generated by neuroepithelial cells' sodium transport and that these stem cells disappear at later stages of CNS development, it is likely that the electric axon guidance is essential for axon orientation during the period when the long-distance axons start to extend. Galvanotropism precedes chemotropism during CNS development.

\section{References}

1. McCaig CD, Rajnicek AM, Song B, Zhao M (2005) Controlling cell behaviour electrically: Current views and future potential. Physiol Rev 85: 943-978. [PubMed]

2. Yamashita $M(2015)$ Weak electric fields serve as guidance cues that direct retinal ganglion cell axons in vitro. Biochem Biophys Rep 4: 83-88.

3. Yamashita M (2012) Ion channel activities in neural stem cells of the neuroepithelium. Stem Cells Int 2012: 247670. [PubMed]

4. Yamashita M (2013) From neuroepithelial cells to neurons: Changes in the physiological properties of neuroepithelial stem cells. Arch Biochem Biophys 534(1-2): 64-70. [PubMed]

5. Yamashita M (2015) Electrophysiological recordings from neuroepithelial stem cells. Methods Mol Biol 1212: 195-200. [PubMed]

6. Yamashita M (2016) Epithelial sodium channels (ENaC) produce extracellular positive DC potentials in the retinal neuroepithelium. Data Brief 6: 253-256 [PubMed]

7. Yamashita M (2013) Electric axon guidance in embryonic retina: Galvanotropism revisited. Biochem Biophys Res Commun 431(2): 280-283. [PubMed]

8. Deiner MS, Kennedy TE, Fazeli A, Serafini T, Tessier-Lavigne M, et al. (1997) Netrin-1 and DCC mediate axon guidance locally at the optic disc: Loss of function leads to optic nerve hypoplasia. Neuron 19(3): 575-589. [PubMed]

9. Windle WF, Austin MF (1936) Neurofibrillar development in the central nervous system of chick embryos up to 5 days' incubation. J Comp Neurol 63(3): 431-463.

10. Guthrie S (2007) Neurotrophic factors: Are they axon guidance molecules? Axon Growth and Guidance 621: 81-94. [PubMed]

*Corresponding author: Masayuki Yamashita, Center for Medical Science International University of Health and Welfare, 2600-1 Kitakanemaru, Ohtawara 324-8501, Japan, Tel: +8128724 3088; Fax: +81 28724 3100; E-mail: my57@iuhw.ac.jp

Received April 03, 2017; Accepted April 12, 2017; Published May 31, 2018

Citation: Yamashita M (2018) Neural stem cells of the neuroepithelium direct newborn neurons' axons electrically: Galvanotropism precedes chemotropism. J Stem Cell Res Ther: 428

Copyright: () 2018 Yamashita M. This is an open-access article distributed unde the terms of the Creative Commons Attribution License, which permits unrestricted use, distribution, and reproduction in any medium, provided the original author and source are credited. 